\title{
SIJEPPU ADA PAPPASENNA TOMATOWAÉ MEMBINCANG MEDIA AHMADIYAH
}

\author{
Sijeppu Ada Pappasenna Tomatowaé \\ The Discussion of Ahmadiyah Media
}

\author{
Husnul Fahimah Ilyas \\ Balai Penelitian dan Pengembangan Agama Makassar \\ Jl. A.P. Pettarani No. 72 Makassar \\ Email: husnul_natalia@yahoo.com
}

Naskah diterima tanggal 7 Desember 2012. Naskah direvisi tanggal 20 Desember 2012. Naskah disetujui tanggal 4 Januari 2013

\begin{abstract}
Abstrak
Tulisan ini menguraikan tentang media tulis Ahmadiyah Sijeppu Ada Pappasenna Tomatowaé yang spesifik dengan nuansa lokal. Lektur ini diramu sedemikian rupa dengan simbol-simbol budaya lokal untuk memperteguh ajaran Ahmadiyah, melalui pesan leluhur orang Bugis mengenai kehidupan manusia yang saling bertikai satu sama lain, kemudian datanglah seseorang yang bisa memperbaiki kehidupan manusia yang digelar "Topute Innong Kinnongnge". Sosok tokoh To Pute Innong Kinnongnge dikaitkan dengan ajaran Ahmadiyah semisal dalam cara memegang pemerintahan, menunjukkan jalan kesepuluh, dan sebagai Tomanurung yang menegakkan adat dan agama di tanah Bugis. Hal ini mengindikasikan interpretasi dari pemaknaan simbol yang digunakan sangat memudahkan dalam memahami ajaran Ahmadiyah.
\end{abstract}

Kata kunci: Ahmadiyah, Sijeppu Ada Pappasenna Tomatowaé, Topute Innong Kinnong, lektur, Bugis

\begin{abstract}
This paper describes the printed media of Ahmadiyyah media with the title 'Sijeppu Ada Pappasenna Tomatowae' which is specifically local nuances. The literature was designed in such way with the symbols of local culture to strengthen the Ahmadiyyah teaching through the messages of Bugis ancestors about human life which was always in a conflict each other. Then someone came who could mend the people's live called Topute Innong Kinnongnge. The figure of Topute Innong Kinnongnge was associated with Ahmadiyah teaching, for instance the ways to manage governance, to show the tenth way as Tomanurung who enforced culture and religion in Bugis land. This indicates that the interpretation of the symbol meaning used facilitates to easily understand the Ahmadiyyah teachings.
\end{abstract}

Keywords: Ahmadiyyah, Sijeppu Ada Pappasenna Tomatowaé, Topute Innong Kinnong, Literature, Bugis

\section{PENDAHULUAN}

$\mathrm{L}$ ektur Sijeppu Ada Pappasenna Tomatowaé adalah lektur khas tipikal Bugis yang sangat populer di kalangan masyarakat. Saking populernya sehingga banyak versi cerita yang bisa terungkap dari berbagai segmen. Fenomena ini mengesankan bahwa cerita ini lebih sebagai folklore kemudian alur kisahnya ditulis dalam lontaraq atau lektur klasik.
Muatan lektur ini berisi cerita tentang kondisi kehidupan akhir zaman. Akhir zaman yang dimaksud bukan dunia kiamat dan berakhirnya kehidupan dunia, tapi dipahami sebagai kondisi kehancuran yang mengindikasikan berakhirnya satu "fase" kehidupan manusia. Fase kehidupan ini bukanlah sebuah perkembangan kronologis kehidupan peradaban yang menggambarkan perkembangan pemikiran dan teknologi semacam orde kehidupan, melainkan fase kehidupan manusia 
yang sudah mencapai titik kulminasi kejenuhan yang mengarah pada kehancuran dan fase kehidupan manusia akan dimulai lagi dari titik nol.

Bagi masyarakat Bugis, kisah yang tertuang dalam media lektur Sijeppu Ada Pappasenna Tomatowaé dipahami dalam bentuk mitologi. Mitologi ini terkait dengan keyakinan keagamaan yang dianut masyarakatnya. Dan nilai-nilai ajaran kehidupan yang ada di dalamnya dinilai memiliki kekuatan universal yang berlaku bagi semua ummat manusia di muka bumi ini (Ahmad, 1993).

Di Sulawesi Selatan ada banyak ormas, kelompok dan sekte keagamaan Islam, mulai dari ormas besar semacam NU dan Muhammadiyah, aliran tarekat yang masuk ke dalam kategori tarekat muktabarah, serta kelompok-kelompok sempalan, baik yang asli (genuine), lahir dari lokalitas maupun yang datang dari luar. Dari keseluruhan kelompok yang disebutkan, sampai sekarang ini belum ditemukan adanya suatu kelompok keagamaan yang menpergunakan media lokal (lektur) sebagai media sosialisasi ajaran. Sangat berbeda dengan Ahmadiyah yang nota bene lahir dan berkembang di India dan masuk ke Indonesia, justru mempergunakan lektur lokal sebagai media sosialisasi ajarannya.

Penggunaan lektur lokal sebagai media sosialisasi ajaran keagamaan dalam ilmuilmu humaniora dapat ditinjau dari berbagai perspektif. Tinjauan antropologis bisa melihat dari sisi akulturasi kebudayaan yang meninjau asimilasi nilai kebudayaan Bugis dan Ahmadiyah. Kajian sejarah akan mengantar pada pengaruh perkembangan Bugis terhadap Ahmadiyah ataupun sebaliknya. Sedang dari sisi analisis wacana dan kajian teks filologis akan mengantar kita pada sisi legitimasi penggunaan lektur lokal terhadap ajaran Ahmadiyah. Legitimasi yang dimaksud adalah apakah kehadiran Mirza Ghulam Ahmad memiliki kesesuaian mitologis bagi masyarakat Bugis atau sekadar kebetulan, ataukah lektur lokal ini dicaplok untuk mengesahkan kehadiran Ahmadiyah seperti yang terjadi pada salah satu partai politik pada Pemilu 1971 yang mencaplok lektur ini sebagai bahan sosialisasi partai.

Sehubungan dengan latar belakang maka permasalahan yang diangkat dalam penelitian ini berfokus pada: Apakah media Sijeppu Ada Pappasenna Tomatowaé sesuai dengan penerapan ajaran Ahmadiyah?; Apakah isi media lektur tersebut?; dan Bagaimana model sosialisasi yang dilakukan oleh Ahmadiyah dalam menyebarkan ajarannya pada masyarakat muslim di Sulawesi Selatan?. Tujuan penelitian ini adalah untuk mengetahui dan mendeskripsikan secara spesifik Sijeppu Ada Pappasenna Tomatowaé yang dipakai dalam pengembangan dan cara mensosialisasikan ajaran lewat lektur yang ditulis di kalangan jemaat Ahmadiyah.

Metode yang digunakan dalam penelitian ini adalah deskriptif-kualitatif dan metode analisis isi. Tekhnik pengumpulan data dengan cara melakukan observasi, wawancara mendalam, studi pustaka dan kajian dokumen naskah kemudian menganalisisnya. Penelitian ini dilakukan di masyarakat Bugis Sulawesi Selatan. Data yang dikumpulkan dalam penelitian ini berupa data primer dan sekunder. Sumber data primer berupa data lisan yang diperoleh dari mubalig Ahmadiyah, dan beberapa masyarakat yang berkaitan langsung dengan penelitian ini. Sedangkan data sekunder yaitu data tertulis berupa media dalam bentuk buku Sijeppu Ada Pappasenna Tomatowaé (Sejemput Nubawah Orang Tua Bugis) dan bahan bacaan yang berkaitan dengan penelitian ini.

\section{Kajian Teori}

Kajian lektur keagamaan jemaat Ahmadiyah Indonesia sebagai media sosialisasi ajaran agama pada komunitas muslim menggunakan teori simbol dan budaya. Simbol-simbol keramat tertentu memuat makna dari hakikat dunia dan nilainilai yang diperlukan seseorang untuk hidup di dalam masyarakatnya. Simbol-simbol keagamaan semacam itu mampu menggiring bagaimana seseorang merasa cocok untuk melihat, berpikir, dan bertindak. Lebih spesifik dijelaskan bahwa simbol itu adalah rumusan-rumusan yang kelihatan dari pandangan-pandangan, abstraksi-abstraksi dari pengalaman kemudian ditetapkan dalam bentukbentuk yang indrawi, perwujudan-perwujudan konkrit dari gagasan, sikap, putusan, ataupun keyakinan (Geertz, 1992).

Jika kebudayaan dibaca secara semiotik, maka ia merupakan reaksi dari competence yang dimiliki oleh koloni suatu masyarakat untuk mengenal lambang-lambang, kemudian mengiterpretasinya untuk menghasilkan sesuatu (Zoest, 1992: 96).

Budaya bisa dimaknai sebagai keseluruhan pengetahuan manusia sebagai mahluk sosial, yang digunakan untuk menginterpretasi dan memahami lingkungan yang dihadapi dan untuk menciptakan serta mendorong terwujudnya kelakuan. Untuk 
menghegemoni dalam politik kebudayaan bisa dilakukan dengan ungkapan atau simbol suatu makna (Duija, 2005: 117-122).

Media lektur Sijeppu Ada Pappasenna Tomatowaé akan dilakukan proses alih aksara dari huruf lontaraq ke dalam aksara latin agar lebih mudah dibaca oleh publik, adapun proses alih aksara ini dilakukan dengan cara: perpragraf sesuai dengan isi cerita dalam teks. Kemudian dilanjutkan proses penerjemahan dengan cara penerjemahan secara runtut, mulai dari lembaran pertama hingga terakhir; penerjemahan dilakukan kata demi kata, kecuali hal itu tidak dapat dilakukan, antara lain sebab tidak ditemukan padanannya dalam bahasa Indonesia, maka penerjemahan dilakukan secara bebas menurut konteks kalimat.

\section{PEMBAHASAN}

\section{Potret Ahmadiyah}

Jemaat Ahmadiyah adalah sebuah perkumpulan (organisasi) keagamaan yang terdiri dari anggota (baik laki-laki maupun perempuan) yang telah beriman dan mengaku dengan hati dan ikrar dengan lisan atau tulisan, bahwa segala dakwah (pengakuan kenabian gair syar'i) (Sutrisna, 2008) Hazrat Mirza Ghulam Ahmad as itu benar, dan ia berbaiat kepada khalifah-khalifahnya di zamannya, dan anak-anak orang Ahmadi yang belum aqil baligh.Ahmadiyah didirikan oleh Hadrat Mirza Ghulam Ahmad, Imam Mahdi dan Masih Mau'ud as, yang lahir pada hari Jumat 1835 di Qadia, India, beliau berasal dari keluarga bangsawan dari suku Barlas, dinasti Moghul, asal Parsi yang berhijrah ke India dalam tahun 1530 Masehi.

Hadrat Mirza Ghulam Ahmad tidak pernah mengenyam pendidikan formal karena pada waktu itu belum terdapat sekolah dan perguruan tinggi. Namun ketekunannya dalam mengkaji ilmu tafsir Alquran dan menghabiskan waktu untuk membaca buku-buku di kamar perpustakaan ayahnya. Disamping Alquran dan hadis, kesusastraan Arab, Urdu, dan Parsi juga dikuasainya. Sepeninggal ayahnya, beliau memutuskan segala hubungan duniawi, bangkit membela Islam dan menangkis serangan-serangan yang dilancarkan oleh umat Hindu, Kristen, Sikh, dan lain-lain, baik dalam bentuk tulisan maupun lisan.

Pada tahun 1889, beliau berkhalawat selama 40 hari di kota Hoshiarpur. Pada tahun itu juga, beliau mendakwahkan diri sebagai Mujaddid. Pada tahun 1886 beliau diperintahkan untuk membentuk sebuah jemaat. Pada tanggal 23 Maret 1889 untuk pertama kalinya beliau resmi menerima dari khalayak. Baiat pertama berlangsung di kota Luddhiana. Beliau mendakwahkan dirinya sebagai Imam Mahdi dan Masih Mau'ud pada tahun 1891 Masehi (Jayaprawira, 1997: 11-30).

Setelah Mirza Ghulam Ahmad wafat pada tanggal 26 Mei 1908 di Kota Lahore, kepemimpinan ruhani ini secara estafet diteruskan oleh para khalifah yang dipilih dan diangkat oleh jemaat. Karena keberadaan khalifah ini merupakan penerus misi suci yang diemban oleh Mirza Ghulam Ahmad dan pada hakekatnya seseorang menjadi khalifah itu ditunjuk oleh Allah, maka tunduk dan patuh kepada khalifah sifatnya mutlak karena sikap tersebut merupakan pengejewantahan dari tunduk dan patuh pada Allah SWT, seperti diungkapkan oleh khalifah I, "khalifah itu ditetapkan dan dibentuk oleh Tuhan, sesudah itu juga siapa saja yang menjadi khalifah, Tuhanlah yang akan tunjuk dia sebagai khalifah. Mereka yang baiat ditangannya berkewajiban taat sepenuhnya kepadanya".

Sikap tunduk dan patuh terhadap pimpinan ruhani dijabarkan dalam kesediaan anggota mempertahankan doktrin ajarannya dan membayar candah atau iuran pengorbanan (Jemaat Ahmadiyah Indonesia, 2007). Dikalangan jemaat Ahmadiyah ada keharusan atau anjuran membayar candah yang sangat banyak jenisnya berdasarkan peruntukannya. Macam-macam candah itu diantaranya: candah wajib, meliputi Hissa Ahmad, (Hissa Ahmad adalah merupakan bagian dari candah wasiat peruntukannya untuk kegiatan jemaat.) dibayar oleh musi (orang yang berwasiat dengan besaran ${ }^{1} /{ }_{10}$ dan $1 /{ }_{3}$ dari penghasilan si musi, Hissa Jaidad, dengan besaran $1 /{ }_{10}$ dan $1 /{ }_{3}$ darijumlah harta kekayaan si musi, candah Jalsah salamah, dengan besaran $1 /{ }_{120}$ dari penghasilan anggota setiap bulan (Haq, 1982) Dan masih banyak candah-candah yang lainnya. Hasil dari pungutan ini dikirimkan ke pusat (Rabwah) untuk kemudian didistribusikan ke berbagai cabang di berbagai belahan dunia untuk kepentingan pertalighan (syiar). Seperti membangun masjid, rumah misi, penterjemahan Alquran ke dalam 50 bahasa di dunia, dan sejak tahun 1994 jemaat ini telah memiliki stasiun televisi yang bernama Muslim Television Ahmadiyah, yang dipancarkan ke seluruh dunia selama 24 jam nonstop, tujuan dan misi MTA ini, penyebaran tauhid Ilahi, ketinggian Alquran dan kebenaran Nabi Muhammad saw. Di samping itu jemaat inipun aktif di berbagai proyek sosial di bawah bendera Humanity First sejak 1982, 
di antara kegiatannya membantu negara-negara miskin di benua Afrika dan daerah-daerah yang dilanda bencana seperti Aceh, Yogyakarta dan lain-lain. Setelah seseorang meyakini (mengimani) kenabian Mirza Ghulam Ahmad sebagai nabi, dia masih diharuskan menyatakan sumpah setia yang diformulasikan dalam ikrar yang disebut baiat.

Seiring dengan perkembangan Ahmadiyah dari tahun ke tahun, sampailah di Indonesia pada tahun 1925 lewat Tapaktuan, Sumatera yang dibawa oleh Rahmat Ali, seorang misionaris Ahmadiyah. Mulai dari sinilah Ahmadiyah berkembang di Indonesia sampai ke Makassar yang dibawa oleh Bapak Maulvi Malik Azis Ahmad Khan pada tahun 1952, selama 2 bulan kunjungan di Makassar dia membaiat seorang warga Belanda bernama Van Kowen yang bekerja sebagai guru di Makassar.

Pada tahun 1960-1964 seorang anggota Jemaat Ahmadiyah dari Purwokerto, Bapak Dasum sebagai guru sekolah teknik di Makassar. Pada tahun 1964, ibu Dra Nurul Muchlisah sebagai dosen di UNHAS, tetapi pada masa ini Ahmadiyah belum terpola sistem tablignya. Di tahun 1968 tepatnya bulan Maret datanglah beberapa jemaat dari Jawa seperti Drs. Abdul Sobur, Letkol Hasan Muhammad, Lettu Yuwono, dan Ir. Zakir Halim, dengan datangnya anggota-anggota ini, maka di Makassar diadakanlah sholat Jumat bersama yang dimulai dari rumah ke rumah, dan berkembanglah sampai sekarang (Ahmad, 2007: 26-32).

\section{Lektur Lokal Ahmadiyah di Sulawesi Selatan}

Setelah mengidentifikasi lektur-lektur Ahmadiyah (Tim Balitbang Agama Makassar, 2009), penulis mendapatkan satu lektur Ahmadiyah yang spesifik dengan konsumsi komunitas lokal pada masyarakat Bugis Sulawesi Selatan karena mengadaptasikan dengan kultur dan budaya setempat. Media yang digunakan berupa buku yang berjudul Sijeppu Ada Pappasenna Tomatowaé (Sejemput Nubuwah Orang Tua Bugis) yang ditulis oleh Mohammad Tahir Ahmad, diterbitkan oleh Yayasan Wisama Damai, Jl. Raya Parung-Bogor No.27, P.O Box/Parung Bogor 16330 Telp. 082120879, cetakan pertama, Mei 1993, buku ini ditulis dengan tulisan Lontaraq, Arab dan Latin berbahasa Bugis, Arab, dan Indonesia.

\section{Sijeppu Ada Pappasenna Tomatowaé}

Lektur Sijeppu Ada Pappasenna Tomatowaé (Sejemput Nubuwah Orang Tua Bugis) dalam penulisannya terbagi atas dua bagian, bagian pertama ditulis dengan huruf lontaraq, dan bagian kedua suntingan lontaraq, pesan Besse Batara kepada turunannya yang dijadikan acuan penulisan lektur ini, dan bagian ketiga merupakan transliterasi dari tulisan lontaraq sebelumya.

Isi wasiat yang diamanahkan oleh leluhur mengatakan: suatu saat nanti dunia ini akan terjadi kekacauan, manusia saling menupahkan darah seperti ikan memakan anaknya maka sebagian orang berlarian bersembunyi di hutan akan tetapi diterkam macan, sebagiannya lagi terjun ke sungai akan tetapi diterkam buaya, dan sebagian berlarian memanjat pohon akan tetapi dililit ular. Tidak ada satupun yang selamat kecuali orang yang berlindung pada tanah lapang disiang bolong, berteduh di daun Lallumpang, dan berpegang di Cangaduri. Tidak ada yang bisa berlindung di tanah lapang disiang bolong kecuali To Pute Innong Kinnongngé atau orang putih bercahaya, dialah yang bisa selamat jika kekacauan telah terjadi. Siapakah yang dimaksud Topute Innong Kinnong? yaitu orang yang menghidupkan kayu yang mati, menguncupkan tangkai dan ranting kayu yang kering.

Siapakah dia? yaitu empat jenis golongan: pertama seekor ular, kedua kepiting, ketiga udang, dan keempat wujud manusia. Hanya Pute Innong Kinnongngé yang mampu menghentikan kerusuhan di tanah Bugis tersebut. Karena adat istiadat tanah Bugis telah kacau. Jika kedatangan Topute Innong Kinnongngé telah dekat, disedikanlah tujuh kursi di lapangan, diinstrusikan kepada rakyat untuk memilih yang akan menjadi Arung (raja). Raja Mangkau di Bone, Somba di Gowa, Pajung di Luwu, Datu di Soppeng, Matowa di Wajo, Addatuwang di Sidenreng; dan lain-lain.

Sesungguhnya dari ketujuh kursi yang yang disediakan hanya satu yang kosong yaitu kursi To Pute Innong Kinnongngé. Jika kedatangannya sudah dekat dan menyebar dibuatkan rumah yang besar sebagai tempat berkumpul untuk bermusyawarah. Sesungguhnya amanah atau wasiat yang disampaikan menunjukkan pada kejadian yang dinamakan cappa wettu (akhir zaman). Cappa wettu adalah bukan waktu yang akan habis, tetapi merupakan waktu umat manusia mengalami kemajuan di dunia. Pada saat (waktu) munculnya berbagai macam ilmu pengetahuan. Manusia saling bersaing (ingin mengalahkan) yang tidak pernah dibuat oleh orang-orang zaman dulu.

Munculnya berbagai macam ilmu pengetahuan, makin banyak juga kebutuhan hidup di dunia. Semakin tinggi aturan dalam kehidupan 
manusia semakin banyak pula kejahatan di antara umat manusia. Adat-adat yang dijunjung tinggi diganti menjadi adat istiadat yang baru. Anak telah memperbudak orang tuanya, sebagian perempuan memerintah suaminya, perempuan semakin kurang rasa malunya. Dulu neneknya hanya hamba sahaya, dan sekarang telah menjadi bangsawan karena kaya. Silaturahmi antar sesama sudah tidak ada, kecuali ada kepentingan tertentu, tolong menolong sudah langka, uang lebih berkuasa dari pada adat. Umat manusia saling bersaing, orang yang kuat tinggi kedudukannya dan pintar memakan orang yang lemah dan bodoh. Jika tablig Islam semakin gencar dilakukan, maka keyakinananpun semakin hambar. Makin banyak orang yang pintar, kejahatan semakin marak di antara umat manusia. Banyak masjid yang besar, tetapi petunjuk dari-Nya telah hilang.

Bersembunyi di hutan dan diterkam macan menjelaskan macan (harimau) jika ditulis dalam aksara lontaraq, tulisannya bisa dibaca macca. Itulah yang banyak memakan orang bodoh, termasuk orang berpangkat, karena yang menduduki jabatan tentu orang yang pintar. Terjun ke sungai dan diterkam buaya yang dimaksud dengan buaya merupakan kiasan orang yang rakus dan licik dalam memperoleh harta kekayaan dan termasuk pemakan riba, menghisap darah orang kecil atau orang miskin. Memanjat di pohon dan dililit ular dikiaskan pada orang yang bercabang lidahnya, politikus pembohong, suka memeras orang, dialah yang mengikat leher orang yang miskin dan bodoh.

Orang yang berlindung di tanah lapang di siang bolong yaitu orang jujur yang menjalankan agama yang benar, menjalankan silarutarrahim antar sesama manusia. Berkeliaran menembus cahaya artinya bergaul dengan orang banyak. Tunduk pada aturan-aturan pemerintah, tidak mendatangkan keributan dimanapun dia berada. Tidak lain menunjuk pada kaum yang berlindung dari cahaya, yang ingin menegakkan adat istiadat yang dijunjung tinggi dan menghidupkan semangat umat Islam serta menghidupkan syariat Islam menjadi adat istiadat dalam kehidupan umat manusia.

Menghidupkan kayu yang mati, dan menguncupkan tangkai dan ranting yang kering, inilah salah satu misi Topute Innong Kinnongngé. Aturan-aturan syariat, agama dan adat-adat telah mati yang akan dihidupkan kembali yang tidak dijalankan oleh manusia dalam mengatur kehidupan duniawi, berdasarkan pada kitab suci Alquran. (Allah membuat perumpamaan satu kalimat yang baik seperti sebatang pohon yang baik”. (14: 25) Yang dikatakan: pertama ular, kedua kepiting, ketiga udang, dan keempat wujud manusia. Maksudnya, yaitu memperlihatkan contoh kongkrit yang mengatakan: jika hewan telah tua (kulitnya kering) bisa berganti kulit menjadi muda atau bermetamorfosa, itulah yang dikatakan menguncup kembali.

Tomapute Innong Kinnongé diibaratkan dengan Tomanurung yang akan muncul kembali untuk menegakkan adat-adat istiadat yang dijunjung tinggi untuk dipakai mengatur kehidupan penduduk kampung, agar hidupannya adil dan tenteram. Itulah yang dimaksud nadzir dalam Alquran dan dinamakan Tomanurung dalam suku Bugis. Yaitu orang yang diberikan wahyu dan ilmu dari Allah. Itulah sebabnya Tomanurungnge jujur dalam bertutur kata, dan tidak pernah ingkar. Seperti: Tomanurungnge di Matajang (Bone), jika dia melihat segerombolan kerbau yang sedang makan di padang rumput, langsung bisa menyebutkan jumlahnya tanpa harus menghitungnya satu persatu.

Begitu juga orang yang berbelanja di pasar tidak perlu dihitungnya, langsung menyebutkan jumlahnya dan tidak pernah salah. Karena ilmunya langsung diberi oleh Allah Yang Maha Pencipta. Karena ilmunya luas dan dalam diberi gelar Mattasi Lompoe maksudnya luas dan dalam ilmunya.

Tujuh kursi yang diatur di tanah lapang, yaitu diinstruksikan penduduk kampung untuk memilih wakil yang akan menjalankan pemerintahan. Sekarang dinamakan Pemilu (Pemilihan Umum). Pemilu seperti halnya amanah leluhur suku Bugis yang mengatakan: tujuh kursi yang diatur tapi ada satu kursi yang kosong jadi hanya enam orangnya yang duduk dan akan menjadi kepala pemerintahan. Persis Pemilu tahun 1971 di dalam partai agama. Karena waktu itu ada enam partai agama yang ingin menududuki kursi di DPR. Yang dimaksud kursi kosong yaitu ada satu golongan agama tidak menjaga pemerintahan. Yang dia dituntut, ingin mengamalkan aturan adat Islam di dalam kitab suci Alquran, yaitu jalan yang bersih, jalan yang lurus atau jujur, adil, itulah yang dinamakan jalannya Topute Innong kinnongngé.

Bilangan tujuh dalam kitab suci Alquran bilangan sempurna, ataukah bilangan genap, bukan bilangan satu sampai tujuh semata-mata. Seperti di dalam Alquran yang mengatakan tujuh lapis tanah, tujuh lapis langit artinya "banyak dan sempurna". Pemilu 1971 sejalan dengan amanah (wasiat) orang 
Bugis karena waktu itu sempurna bilangan yang akan dipilih terdapat sepuluh tanda gambar partai yang akan dipilih. Serta sejalan Topute Innong Kinnong, yaitu sepuluh juga.

Kehidupan yang adil bagi penduduk kampung di akhir zaman, mempunyai sepuluh jalan atau sepuluh aturan-aturan, yaitu: Pertama, tidak menduakan (musyrik) Allah Ta’ala sampai masuk ke liang lahad. Kedua, senantiasa menghindarkan diri dari perbuatan buruk (zina, berbohong, berdusta, pandangan birahi, membuat keributan, dan pemberontakan), serta tidak akan dikalahkan oleh gejolak hawa nafsunya. Ketiga, Senantiasa mendirikan sholat lima waktu, sesuai perintah Allah Ta’ala dan Rasul-Nya. Sedapat mungkin berusaha melaksanakan sholat sunat Tahajjud, selalu bertasbih kepada Allah, serta mengirimkan sholawat kepada Nabi Muhammad saw setiap hari (waktu). Keempat, tidak akan mendatangkan kesusahan dan tidak akan menyakiti semua makhluk Allah dan khususnya umat Islam melalui lidah, tangan atau melaui caracara lainnya.

Kelima, berpengang teguh dan tetap setia kepada Allah Tảala, dalam setiap kondisi rela terhadap apa yang diputuskan Allah terhadap dirinya. Tidak memilih kadaan, baik dalam keadaan susah maupun senang, menerima dengan ikhlas karena Allah. Senantiasa menanggung segala kehinaan serta kesusahan dan kepedihan di jalan agama-Nya tidak memalingkan mukanya dari Allah Ta'ala ketika ditimpa suatu musibah, melainkan semakin mendekatkan diri kepada-Nya. Keenam, akan berhenti dari adat kebiasaan buruk dan melawan hawa nafsunya. Mengikuti sepenuhnya perintah Allah di dalam Alquran dan sabda RasulNya Muhammad saw sebagai pedoman pada setiap kehidupannya. Ketujuh, meninggalkan sifat takabur dan kesombongan sepenuhnya, dan akan menjalani hidup dengan merendahkan diri, kerendahan hati, budi pekerti baik, lemah lembut, dan sederhana.

Kedelapan, agama dan kehormatan agama serta solidaritas Islam akan dia anggap lebih mulia dari pada nyawanya, hartanya, anak turunannya, dan segala yang dicintainya. Kesembilan, menolong orang (solidaritas terhadap makhluk-Nya) sematamata karena Allah Tảala, karena menggunakan yang dinikmatkan dan dikaruniakan Allah kepadanya, bisa mendatangkan manfaat (kebaikan) bagi umat manuisa.

Kesepuluh mengikat tali persaudaraan dengan Topute Innong Kinnongyang diturunkan (dibawanya) karena persaudaraan yang paling tinggi derajatnya yang tidak memperoleh bandingan dalam ikatan persaudaraan maupun hubungan-hubungan dunia dan segala bentuk penghikmatan penghambaan.

Amanah mengenai kejujuran juga disebutkan misalnya biar daun pisang yang kering tidak diambilnya jika tidak memintanya; rumput, tangkai, atau ranting yang kering tidak diambilnya kalau tidak ingin menggunakannya; serta tidak ada kebohongannya; teguh pada keyakinannya dan tidak bergeser meskipun pekerjaan yang dijalankannya sangat sulit. Begitulah yang sering dikatakan jujurteguh-perkataan yang benar.

Akan tetapi dunia telah rusak karena adat Islam yang dijunjung tinggi telah rusak. Kejujuran telah hilang, apa yang dikatakannya, berbeda dengan perbuatannya. Orang tidak berani lagi tegakkan kejujuran karena pahit rasanya. Kejujuran telah hilang, keteguhan atau komitmen telah hilang.

Itulah sebabnya Allah menurunkan Topute Innong Kinnong yang telah ditentukan-Nya dan ditunjukkan di kampung India. Dari keturunan bangsa Persia serta dari keturunan Fatimah putri Nabi Muhammad SAW yang telah dijanjikan oleh Allah di dalam kitab suci Alquran dan yang telah dijanjikan oleh Nabi Muhammad saw di dalam hadis shahih. Orang itu muncul pada tahun 1835, dan menegakkan dan menjalankan perintah yang diberikan Allah pada tahun 1889, itulah yang telah diaturkan dari Allah "sepuluh jalan" seperti yang telah dituliskan di atas.

Tepat seratus tahun setelah mengabarkan diri menjadi manusia pilihan Allah Ta’ala, yang ditunggu kedatangannya dari umat manusia di dunia, pada tahun 1989, muncullah kaumnya di tanah Bone. Akan tetapi kaum itu seperti rumah, hanya tiangnya yang berdiri di Tanah Bone. Sama halnya jumlah tiang rumah adat yang didirikan di Matajang yaitu 89 tiang. Seakan-akan menunjukkan mengatakan kaum Topute Innong Kinnong muncul di Tanah Bone tahun 89 (1989).

Amanah leluhur juga mengatakan: "kalau kursi telah diatur dan belum muncul orang yang punya kursi kosong, dibuatkanlah rumah besar, yang akan ditempati duduk bersama dan bermusyawarah kalau telah tiba kedatangannya". Sesungguhnya rumah yang dibuat untuk menunggu Topute Innong Kinnongnge yaitu "masjid" serta rumah markas sebagi tempat menjalankan dan menyebarkan agama Islam (aturan adat yang sempurna), yang pernah diturukan Allah Ta’ala kepada Nabi kita Muhammad saw. 
Di rumah markasnyalah Topute Innong Kinnongnge mengumpulkan golongannya setiap tahun, dinamakan jalsa salanah, maksudnya: "semua berkumpul duduk bersama dalam kesederhanaan untuk beribadah kepada Allah Ta’ala, serta mendengarkan nasihat dan menambah ilmunya, yang bisa menambah keyakinannya.

Ada juga amanah yang mengatakan: "Jikalau rakyat telah memilih dan yang punya kursi kosong belum muncul (karena berlindung di siang bolong), tiba-tiba kembali jalan-jalan di pasar Bone, kentut besarlah dia ditengah pasar. Ribut orang-orang yang berbelanja di pasar, mengatakan ("siapakah yang kentut sangat besar semua orang yang berbelanja di pasar Bone mendengarnya") akan tetapi bau busuk kentutnya menyebar pada tanah pemerintahan Bone".

Amanah (wasiat) ini disalin dari lontaraq yang disimpan Ijapa Daeng Pawello anak dari Imappa Daeng Mawelle dari Kawerang Cina Bone, disalin di Pare Mananti Pulo Kijang tanggal 7 Agustus 1971. Amanah ini sangat langka orang yang dapat mengerti dan memahaminya. Akan tetapi kenyataannya, ketika rakyat telah memilih (Pemilu) pada tahun 1971, bersamaan pada saat rumah adat di Matajang Watampone dibuat, ada kaum Topute Innong Kinnongnge kembali ke tanah Bugis, Oktober 1972.

Tiba-tiba dia ditahan di dalam penjara di tengah Kota Watampone. Tidak ada perlakuannya yang melanggar aturan pemerintah padahal baru tiba dari Pulo Kijang dan langsung melaporkan diri pada pemerintah, yang pertama pada kepala dusun di Lateppa, kepala desa di Lapeccang, camat di Cina, Kapolsek dan Koramil di Cina. Beliau membawa KTP, surat pindah berdomisili dari Pulo Kijang ke Bone, surat kelakuan baik dari polisi di Pulo Kijang, surat tidak terlibat G/30 S PKI dari polisi di Pulo Kijang. Tiga hari setelah melaporkan diri, tiba-tiba Babinsa datang mengambil bukunya, dibawa ke Kantor Kodim Bone.

Belakangan langsung di masukkan dalam penjara (sel) di Watampone tanpa diintrogasi, tanpa diselidiki terlebih dahulu. Waktu itulah yang dinamakan "di tengah pasar Bone bunyi kentutnya sangat besar" yang tersebar di tanah Bone hanya bau busuk kentutnya Topute Innong Kinnongnge. Karena mulai dari Watampone sampai di sebelah Timur Bajo, terus sampai di sebelah Barat di tanah Batu Lappariaja, langsung di Pompanua sampai naik ke Kahu Bontocani, Camming (Palattae), disebarkan kebusukannya itu.
Ratusan orang yang dipenjara pencuri, perampok, pembunuh, pezina dan tindakan kejahatan lainnya, yang tidak disebarkan kejahatannya. Kaum Topute Innong Kinnongnge kaget dikatakan jelek (sesat), membuat agama baru, mengganti Nabi Muhammad, ingin merusak agama Islam. Orang Bone saat itu tidak memahami bahwa dialah yang dikatakan sebagai kaum yang berlindung di tanah lapang di siang bolong kaumnya Topute Innong Kinnongnge, yang dinantikan oleh orang Bone.

Rumah Adat Matajang Watampone, sebetulnya rumah adat itu menjadi bukti atau sebagai contoh rumah adat suku Bugis, seperti suku bangsa lain, yang mempunyai rumah adat masing-masing. Kita bisa melihat berbagai macam rumah adat suku bangsa di Indonesia, di Taman Mini Indonesia Indah (Jakarta timur). Niatnya bukan karena menunggu munculnya Topute Innong Kinnongnge dan tidak ingin dijadikan angadekeng (menyembah), menyembah berhala kecuali Puang Allah-Ta'ala. Akan tetapi semata-mata sebagai tanda bukti aturan adat orang Bugis yang juga mempunyai rumah adat.

Kekacauan di dunia yang telah dijelaskan sebelumnya, bisa jadi terdapat perang besar melebihi waktu Nipon (Jepang), yang dinamakan Perang Dunia III. Karena seakan-akan orang tuatua (leluhur) memahami yang akan terjadi dengan mengatakan "sebentar ada orang yang berjuang di dalam agama bersembunyi bergerilya di dalam hutan, seperti yang telah dijalankan DI/TII Kahar Muzakar di Sulawesi, serta Imam Karto Suwiryo di Jawa, Daud Beureuh di Aceh, seperti halnya perjuangan Yaser Arafat di Palestina.

Berpegang di canaguri yaitu berpegang pada pemerintah (legal). Dimanapun kaum yang berlindung di tanah lapang di siang bolong, jelas berpegang pada pemerintahnya, tidak ada yang membuat pemberontakan. Berbeda caranya dengan gerilyawan yang bersumbunyi di dalam hutan.

Tidak duduk pada kursi yang disediakan karena bernaung di daun lallumpang. yaitu tanda Gambar Golkar tahun 1971. Beringin dalam gambar golkar, seperti daun lallumpang. Ada seorang yang bernama M. Jafar Daeng Pawello, ketika hendak mengikuti pemilihan tahun 1971, dia salat istiharah di Pare Mananti Pulo Kijang selama tiga bulan terus menerus, mana yang benar dicoblos, karena sepuluh tanda gambar yang akan dipilih. Enam tanda gambar partai agama. Pertama mendapatkan jawaban dari Allah mengatakan, bukalah matamu 
yang benar yaitu yang membuka simpulnya Petta Torisompaé (Aru Palakka) di Campalagi. Tidak mempunyai tanda gambar, tidak mengejar pemerintahan, itulah yang berlindung di tanah lapang di siang bolong. Kembali melakukan rutinitas tersebut sampai mendapat jawaban yang berinisial huruf (alif) dan (mim) jika berbahasa Arab. Akan tetapi dalam bahasa Bugis huruf (aleepu) dan (sa) yang menghimpun sepuluh tanda gambar yang akan dicoblos (dipilih). Akan tetapi kamu sebagai rakyat mesti memilih dalam pemilihan, berpegang dan ikutlah pada nenek moyangnya orang Bugis, yang mengatakan: bernaunglah di bawah daun lallupangng, yaitu tanda gambar Golkar berteduhlah kamu di situ.

Itulah keputusan dari Allah yang ditunjukkan dalam salat istihara Daeng Pawello di Pare Mananti Pulo Kijang tahun 1971. Menyebabkan penduduk di Pare Mananti diperintahkan agar memilih tanda gambar Golkar. Pada tahun itu $100 \%$ penduduk di Pare Mananti Pulo Kijang, memilih Golkar.Jadi kaum Topute Innong Kinnongnge, tidak menjadi anggota di Golkar, tetapi dia berteduh (memberikan suaranya ke Golkar). Karena Pute Innong Kinnongnge jalannya sepuluh, baik jika menghimpun semua jalan sepuluh tanda gambar partai di tahun 1971.

Masih banyak lagi pesan (wasiat) orang tua dulu yang tidak tertulis dalam buku ini, tetapi ada yang paling sering dikemukakan leluhur di kampng-kampung yakni: "jikalau Bone dalam kedaan miring tempatilah pinggirannya, jikalau tengkurap, duduklah di belakangnya, jikalau hangus sembahlah abunya". Yang ingin ditegakkan di tanah Bone yaitu "aturan adat istiadat". Maksudnya dimanapun kita berada harus berpengang pada adat istiadat, di tanah Bugis. Contohnya: toleransi antar sesama, merendah diri dan tidak sombong (angkuh), menegakkan kebenaran, pengayom, jujur (apa yang dikatakan, itulah yang dikerjakan), farda (tabir) antara laki-laki dan perempuan.

Beserta pemerintahan Bone awal mula berdirinya kerajaan seperti cara pemerintahan Islam waktu Khalifah Rasyidin dulu di Madinah. "Mangkau (gelar raja di Bone)" artinya mengerjakan, menjalankan pekerjaan. Mengerjakan dan menjalankan adat-adat, begitu juga yang dinamakan "Khalifah" yaitu yang menjalankan aturan-aturan syariat yang muncul dari nabi-nabi, mewujudkan aturan agama yang di bawa oleh nabi. Wujudkan Mangkau (sistem pemerintahan kerajaan), dan mengerjakan adat-adat yang di bawah Tomanurung.
Kapal yang akan muncul, terdapat wasiat leluhur mengatakan: "jika telah muncul kebenaran di Bone muncullah Tomallinrungnge ri tana ésoé", akan ada kapal yang muncul, mengangkut semua orang Bugis keluar pulau Sumatera, Kalimantan, Jawa, Ambon, Irian, Malaysia, semuanya dikembalikan ke tanah Bugis.

Sesungguhnya kapal itu bukan kapal besi seperti kapal Pelni, bukan kayu seperti kapal Pinisi yang dibuat oleh orang Bira, bukan pula kapal Fery seperti di Bajoe, akan tetapi kapal itu dibuat oleh Allah, sebagai alat transportasi To Pute Innong Kinnongnge beserta kaumnya. Itulah yang akan ditumpangi oleh umat manusia kembali ke aturan adat istiadat Bone (Bugis). Kapal safinatun itu, seperti yang telah ditumpangi Nabi Musa as, sesuai dengan Alquran. (Dan hamba Allah-Taala disebutkan dalam Alquran "Abdan", Surah Kahfi ayat 66. Kapal itu selalu di lobangi (dibocorkan) dari penumpangnya, dan semakin banyak manusia yang melubangi (membocorkan) kapal itu)

Kapal dalam firman Allah seperti perkataan dalam wasiat yang mengatakan harta kekayaan, seperti: tanah, rumah, tanaman, emas, perak, kendaraan, hewan, uang, semuanya dinamakan safinah dalam kitab suci Alquran. Sedangkan yang dimaksud tanah Bugis, yaitu adat istiadat suku Bugis. Adat di tanah Bugis dahulu diturunkan untuk Tomanurung.

Jadi makna wasiat tersebut, harta kekayaan yang direzkikan Allah kepada kita, wajib kita mengaturnya sesuai dengan ketentuan adat pada zaman dulu. Seperti yang difirmankan Allah dalam kitab suci Alquran. (yang mengatakan: "dan dari apa-apa yang telah Kami rezkikan mereka, mereka membelanjakan" 2: 4). Surah Kahfi menjelaskan(QS.18: 97) yang mengatakan: "dan dari apa-apa yang telah Kami rezkikan mereka, mereka membelanjakan". (2: 4).berikanlah kepadaku kepingan-kepingan besi. Kepingan-kepingan besi yang dimaksudkan di sini yaitu emas, perak, atau harta kekayaan. Inilah yang nantinya dikumpulkan untuk dibuat tembok penghalang dari kaum Topute Innong Kinnongnge bersama Ya’juj dan Ma’juj. Dalam Alquran Surah Kahfi dinamakan juga Topute Innong Kinnongnge yang ditunggu, karena Zulqarnain (pendamping wali). Kapal itu pula yang disebutkan dalam Alquran yang mengatakan "Perahunya Nabi Nuh".

Karena wasiat yang dinamakan Pute Innong Kinnong disebut juga sebagai Nabi Nuh yang kedua, 
nanti akan datang atau muncul pada ujung waktu membuat perahu kapal untuk menampung semua orang-orang yang beriman. Agar selamat dari pengaruh hawa nafsu, harta kekayaan, dan nafsu syahwat. Karena di akhir zaman nanti umat manusia semakin banyak dipengaruhi harta kekayaan dan nafsu birahi. Mudah-mudahan penjelasan ini menjadi buah pikiran, umat Islam suku Bugis menerima dengan baik. Agar kita mendapat petunjuk dari Allah Yang Maha Pencipta.

\section{Model Sosialisasi Ahmadiyah}

Penulisan media cetak yang dilakukan oleh Mohammad Thahir dapat dilacak melalui sisipan dalam kisah Sijeppu Pappasenna Tomatowaé yang mengatakan bahwa: Amanah yang dituangkan dalam kisah ini berdasarkan lontaraq koleksi Muhammad Jafar Daeng Pawello bin Imappa Daeng Mawelle bin Lamannu Daeng Mallejja berasal dari Kawerang Cina Tanah Bone, yang disalin di Pulo Kijang Indragiri tanggal 7 Agustus 1971. Kisah ini juga ditambahkan dari berita televisi stasiun Ujung Pandang pada malam Kamis tanggal 14 Pebruari 1984 di rumah bapak Umar di Jl.Tamalate Perumnas Ujung Pandang. Sebagian pula bersumber dari pemaparan narasumber atau orang tua tentang amanah leluhur di Lateppa, di Watampone, di Pulau Kijang, dan di Danai-Riau.

Sijeppu Ada Pappasenna Tomatowaé(Sejemput Nubawa Orang Tua Bugis) sebagai salah satu lektur keagamaan Ahmadiyah yang sangat spesifik dengan masyarakat Sulawesi Selatan khususnya suku Bugis karena memiliki ciri khas tersendiri dibandingkan lektur yang lainnya seperti cara menuliskan dengan memakai aksara lontaraq, gaya penulisan, pemilihan diksi yang tepat, dan simbol-simbol yang digunakan sehingga sangat mudah dimengerti dan dipahami oleh masyarakat asli suku Bugis terutama yang bisa membaca dan mengerti bahasa Bugis.

Sedangkan dari segi isi dan penjelasan dalam lektur tersebut bersentuhan langsung dengan kultur budaya lokal masyarakat setempat. Lektur Sijeppu Ada Pappasenna Tomatowaé (Sejemput Nubawah Orang Tua Bugis) berisi tentang ajaran-ajaran Islam yang berkaitan dengan ajaran Jemaat Ahmadiyah.

Ajaran Islam yang tertuang dalam lektur ini sesuai dengan pemahaman Jemaat Ahmadiyah yang berisi pertama, keadaan umat Islam zaman sekarang yang sudah terpecah-pecah menjadi beberapa golongan dan keadaan umat Islam yang mulai rusak, kedua pemeliharaan Allah swt terhadap
Islam; Ketiga cara Allah swt memperbaiki umat Islam yang rusak dengan jalan menurunkan Nabi atau Nazir di muka bumi ini yang disimbolkan Pute Innong-kinnong di tengah-tengah masyarakat suku Bugis yang disebut Tomanurung.

Keempat, tanda-tanda akhir zaman, kelima cara Topute innong-kinnongnge memimpin; keenam Seppulo laleng apaccingeng (Lalenna Topute Innong Kinnongnge); ketujuh tanda-tanda Nabi atau Nazir yang akan datang. Lektur Sejemput Nubawa Orang Tua Bugis berasimilasi dengan ajaran Ahmadiyah dan budaya Bugis, dalam hal ini Jemaat Ahmadiyah Indonesia menggunakan atau "meminjam" simbolsimbol budaya Bugis untuk menafsirkan ajaran Ahmadiyah. Simbol-simbol keagamaan yang dianggap "keramat" dan substantif digiring ke dalam pemahaman dan kesadaran budaya orang Bugis, sehingga orang Bugis merasa "cocok" untuk melihat dan bertindak serta berfikir seperti "Ahmadiyah".

Kehadiran Mirza Ghulam Ahmad di dunia ini, di dalam Lektur tersebut tidak disebutkan namanya, akan tetapi secara implisit dijelaskan secara gamblang, dan jika kita lebih mendalami kajian ini maka dapat ditemukan bahwa yang dimakasud dengan Topute Innong Kinnongnge adalah salah satu simbol yang dipakai oleh Tahir Ahmad (penulis lektur Sijeppu Ada Pappasenna Tomatowaé) merujuk pada Mirza Ghulam Ahmad seperti yang dijelaskan dalam tulisannya bahwa:

Pertama masalah pemerintahan Topute Innong Kinnongnge mempunyai sepuluh jalan atau sepuluh aturan-aturan (Ahmad, : 1998), yaitu:

1. Tidak menduakan (musyrik) Allah-Tảala sampai masuk ke liang lahad.

2. Senantiasa menghindarkan diri dari perbuatan buruk (zina, berbohong, berdusta, pandangan birahi, membuat keributan, dan pemberontakan), serta tidak akan dikalahkan oleh gejolak hawa nafsunya.

3. Senantiasa mendirikan shalat lima waktu, sesuai perintah Allah Táala dan Rasul-Nya. Sedapat mungkin berusaha melaksanakan shalat sunat tahajjud, selalu bertasbih kepada Allah, serta mengirimkan sholawat kepada Nabi Muhammad saw setiap hari (waktu).

4. Tidak akan mendatangkan kesusahan dan tidak akan menyakiti semua makhluk Allah dan khususnya umat Islam melalui lidah, tangan atau melaui cara-cara lainnya.

5. Berpengang teguh dan tetap setia kepada Allah Ta’ala dan dalam setiap kondisi dan rela terhadap 
apa yang diputuskan Allah terhadap dirinya. Tidak memilih-milih keadaan, baik dalam keadaan susah maupun senang, menerima dengan ikhlas karena Allah. Senantiasa menanggung segala kehinaan serta kesusahan dan kepedihan di jalan agama-Nya tidak memalingkan mukanya dari Allah-Taala ketika ditimpakan suatu musibah, melainkan semakin mendekatkan diri kepada-Nya.

6. Akan berhenti dari adat kebiasaan buruk dan melawan hawa nafsunya. Akan ikut sepenuhnya perintah Allah di dalam Alquran dan sabda Rasul-Nya Muhammad SAW sebagai pedoman pada setiap kehidupannya.

7. Meninggalkan sifat takabur dan kesombongan sepenuhnya, dan menjalani hidup dengan merendahkan diri, kerendahan hati, budi pekerti baik, lemah lembut, dan sederhana.

8. Agama dan kehormatan agama serta solidaritas Islam akan dia anggap lebih mulia dari pada nyawanya, hartanya, anak turunannya, dan segala yang dicintainya.

9. Menolong orang (solidaritas terhadap makhluk-Nya) semata-mata karena AllahTa'ala karena menggunakan yang dinikmatkan dan dikaruniakan Allah kepadanya, yang bisa mendatangkan manfaat (kebaikan) bagi umat manuisa.

10. Mengikat tali persaudaraan dengan Topute Innong Kinnong yang diturunkan (dibawanya) karena persaudaraan yang paling tinggi derajatnya yang tidak memperoleh bandingan dalam ikatan persaudaraan maupun hubungan-hubungan dunia dan segala bentuk penghikmatan penghambaan.

Kesepuluh aturan di atas adalah bai'at yang digunakan oleh Jemaat Ahmadiyah terutama bagi orang-orang yang baru masuk ke dalam jemaat dan juga berguna bagi yang telah lama atau lebih dulu di bai'at. Hal ini sesuai dengan himbauan bai'at Hz. Masih Mau'ud as pada tanggal 1 Desember 1888 yang menerbitkan sebuah selebaran berjudul Tabligh (amanat) yang berisikan:

Di sini saya menyampaikan sebuah amanat lagi, untuk umat manusia umumnya dan khususnya untuk saudara-saudara saya orang Islam. Yakni, telah diperintahkan kepada saya agar orang-orang pencari kebenaran baiat kepada saya untuk mempelajari keimanan sejati, kesucian imaniah hakiki, dan jalan kecintaan Ilahi; serta untuk meninggalkan kehidupan kotor dan kehidupan yang malas dan durhaka. Jadi orang-orang yang menemukan kekuatan ini dalam kadar apa pun pada diri mereka, wajib bagi mereka untuk datang kepada saya, supaya saya ikut serta dalam kedudukan mereka dan akan berusaha merigankan beban mereka. Dan Allah Ta'ala akan memberikan berkat dalam doa serta perhatian saya untuk mereka. Dengan syarat, mereka siap sepenuh hati untuk menempuh persyaratan-persyaratan Rabbaani. Ini adalah perintah Rabbani, yang telah saya semaikan pada hari ini. Berkenaan dengan itu, ilham bahasa Rabb yang diterima oleh Ghulam Ahmad yang artinya: "Apabila kamu telah membulatkan tekad, bertawakkallah kepada Allah. Dan buatlah perahu di hadapan mata Kami dan wahyu Kami. Orang-orang yang baiat kepada engkau sesungguhnya mereka baiat kepada Allah. Tangan Allah ada di atas Tangan mereka." (Ahmad, 1998).

Butir atau aturan yang kesepuluh di atas jelas sekali bahwa yang dimaksud dengan mengikat tali dengan Topute Innong Kinnong adalah Hazra Miza Ghulam Ahmad as yang diyakini oleh jemaat Ahmadiyah Imam Mahdi dan Masih Mau'ud yang telah datang (Rozzaq, 2008: 52-79).

Kedua dijelaskan dalam lektur ini mengenai Topute Innong Kinnong yang telah ditentukan atau yang ditunjuk oleh Allah ditunjukkan di kampung India, dari keturunan bangsa Persia serta dari keturunan Fatimah putri Nabi Muhammad saw. Sebagaimana yang telah dijanjikan oleh Allah di dalam Kitab suci Alquran dan yang telah dijanjikan oleh Nabi Muhammad saw di dalam hadist shahih. Orang itu muncul pada tahun 1835, dan menegakkan dan menjalankan perintah yang diberikan Allah pada tahun 1889 , itulah yang telah diaturkan dari Allah "sepuluh jalan" seperti yang telah dituliskan di sebelumnya.

Hal yang sama telah dijelaskan marwal dalam kata pengantarnya Ahmadiyah Qadianiyah (2008: ix) bahwa menurut pendiri Ahmadiyah Mirza Gulam Ahmad, Ahmadiyah menjalankan misi menghidupkan Islam dan menegakkan syariah Islam, bertujuan meremajakan moral Islam dan nilai-nilai spiritual, untuk menjalankan misi tersebut posisi Mirza Gulam Ahmad mempunyai peranan penting sebagai khalifah (Cheema, 2004: 3-14; Rozzaq: 2008).

Dalam media yang telah dijelaskan sebelumnya, Mirza Ghulam Ahmad dalam dalam konteks budaya Bugis dimaknai sebagai "Topute Innong Kinnonge" dan terkadang dimaknai sebagai 
nazir atau nabi dikalangan suku Bugis diistilahkan "To Manurungnge". Simbol "Topute Innong Kinnonge" dalam konteks budaya Bugis dimaknai sebagai seorang yang putih bersih dan bercahaya yang datang ke dunia ini, untuk memperbaiki kehidupan umat manusia yang karut marut. "Kecocokan" pengertian ini kemudian dibakukan, diperteguh, dan diberlakukan kemudian diulangulang dalam penyebaran ajaran Ahmadiyah.

\section{PENUTUP}

Lektur yang spesifik ditemukan di lokasi penelitian adalah Sijeppu Ada Pappasenna Tomatowaé (Sejemput Nubawah Orang Tua Bugis) yang berbahasa Bugis Bone yang ditulis dengan menggunakan aksara lontaraq Bugis.

Lektur Sijeppu Ada Pappasenna Tomatowaé (Sejemput Nubuwah Orang Tua Bugis) yang bersisi pesan leluhur Bugis tentang kehidupan manusia di dunia ini yang telah mengalami kiamat kecil, kemudian datanglah seseorang yang memperbaiki kehidupan manusia yang digelar "Topute Innong Kinnongnge", selanjutnya menjelaskan tokoh To Pute Innong Kinnongnge dengan mengaitkan ajaran Ahmadiyah seperti cara pemerintahan dan jalan Topute Innong Kinnongnge dan lain sebagainya.

Lektur Sejemput Nubawah Orang Tua Bugis adalah salah satu cara dalam menyebarkan ajaran Ahmadiyah pada masyarakat Bugis. Penggunaan dengan mengunakan simbol budaya lokal sebagai media sosialisasi ajaran Ahmadiyah, sehingga memudahkan pemahaman dan memperlancar penerimaan masyarakat Bugis terhadap ajaran Ahmadiyah.

\section{UCAPAN TERIMA KASIH}

Ucapan terima kasih kepada bapak Dr. Abd. Kadir Ahmad dan Bapak Dr.Arifuddin Ismail yang telah mengarahkan kepada peneliti untuk konsen dan belajar di markaz Ahmadiyah Makassar selama tiga bulan (2008). Selain itu penulis banyak dibantu oleh Mas Angga dalam penelusuran lektur-lektur Ahmadiyah terima kasih juga saya ucapakan, serta terima kasih terkhusus kepada Bapak Syaiful Uyun, Shaleh Ahmadi, dan Murtiono yang telah memberikan akses, informasi, data, dan selalu siap untuk diajak berdiskusi. Terima kasih pula kepada rekan-rekan yang telah memberikan sumbang saran, kritikan, dalam penulisan ini.

\section{DAFTAR PUSTAKA}

Ahmad, Abd Kadir (ed). 2007. Varian Gerakan Keagamaan. Makassar: Indobis Rekagrafis.

Ahmad, Hadhrat Mirza Bashir. 1998. DasarDasarPendidikan Bagi Jemaat. Diterjemahkan oleh R.Ahmad Anwar judul asli Tarbiyyati Jemaat Aur Uske Ushul. Jemaat Ahmadiyah Indonesia.

Ahmad, Mirza Ghulam. 1999. Nasihat Imam Mahdi dan Masi Mau'ud as Mengenai Baiat. ParungBogor. Jemaah Ahmadiyah Indonesia.

Ahmad, Mohammad Tahir. 1993. Sijeppu Ada Pappasenna Tomatowaé: Sejemput Nubuwah Orang Tua Bugis. Parung-Bogor: Yayasan Wisama Damai.

Cheema, H.M.Ahmad. 2004. Khalifah Telah Berdiri. Parung-Bogor: Jemaat Ahmadiyah Indonesia.

Duija, I Nengah. 2005. Tradisi Lisan, Naskah, dan sejarah: Sebuah Catatan Politik Kebudayaan. Dalam "Wacana" jurnal ilmu Pengetahuan Budaya, Vol.7.No.2 Oktober 2005. Depok: Fakultas Ilmu Pengetahuan Budaya Universitas Indonesia.

Dzahir, Ihsan Ilahi. 2008. Ahmadiyah Qadianiyah: Sebuah Kajian Analitis. Jakarta: Balai Penelitian dan Pengembangan Agama Jakarta Badan Litbang dan Diklat Departemen Agama.

Geertz, Clifford. 1992. Kebudayaan dan Agama. Yogyakarta. Kanisius.

Haq, Miyan Abdul. 1982. Pedoman Zakat. Bogor: Jemaat Ahmadiyah Indonesia.

Jayaprawira, Gunawan (ed). 1997. Almasih di Hindustan. Ditulis oleh Mirza Ghulam Ahmad dengan judul asli Masih Hindustan Me dan diterjemahkan oleh Ibnu Ilyas RIS. Parung-Bogor: Jemaat Ahmadiyah Indonesia.

Jemaat Ahmadiyah Indonesia. 2007. Petunjuk Teknis Tahrik Jadid dan Perjanjian Pengorbanan Lainnya. Bogor. JAI

Rozzaq, Abdul. 2008. Muhammad SAW Khatamun Nabiyyin: Tidak Ada Nabi Sesudah Beliau. Parung-Bogor: Jemaat Ahmadiyah Indonesia.

Sutrisna, Muhammad (peny). 2008. Muhammad saw Khatamun Nabiyyin Tidak Ada Nabi Sesudah Beliau. Diterjemahkan oleh Abdul Rozak. Parung-Bogor: Jemaat Ahmadiyah Indonesia. 
Tim Balitbang Agama Makassar. 2009. Hierarki PerkembanganDoktrin Ahmadiyah. Makassar: Departemen Agama RI Balai Penelitian dan Pengembangan Agama Makassar.
Zoest, Aart van. 1992. Peranan Konteks, Kebudayaan, dan Ideologi di dalam Semiotika dalam SerbaSerbi Semiotika. Jakarta: Gramedia Pusaka Utama. 